\title{
Towards More Authentic Learning in Hypermedia
}

\author{
doi:10.3991/ijet.v6iS2.1655 \\ A-M. Tervakari and K. Silius \\ Tampere University of Technology, Tampere, Finland
}

\begin{abstract}
A major challenge in teaching hypermedia is to illustrate how varying dimensions of using context are related to user's quality experience of online services. The Urban Computing Lab (UCL) tool was developed for students to collect rich information for further analysis about quality experiences of online services in authentic situations. Meaningful learning from the real world problems in authentic contexts enhances learning of abstract and theoretical issues.
\end{abstract}

Index Terms-Authentic learning, context-aware service, experience of service, quality of service.

\section{TeAching Challenges In HyPermedia}

High quality and an overall acceptability of online services have become more and more important for users. Smart phones and small laptops enable users to access online services and communities almost everywhere, and contexts of use of online services have become more diverse. The consideration of users' expectations in the design of online services requires an understanding that quality is perceived and experienced subjectively by the user. The quality experience of online services is a complex phenomenon affected by many diverse aspects like usability, accessibility, informational quality, user's physiological and psychological capability, user's personality as well as a situation and a context of use. There are always some permanent dimensions affecting the user's experience such as psychological and physiological traits of human beings (memory, perception, sense, basic needs) and cultural factors, but also some varying dimensions of context of use like the purpose of use, social situation, physiological environment, device used, and emotions and arousal level of user at a given moment. Because of these varying dimensions of context every case of usage is unique and offers the user an unique quality experience [1][2][3][4][5].

One important issue in the teaching of hypermedia is promoting and ensuring the knowledge of quality management and quality evaluation. In addition to professional and theoretical materials, cases and authentic examples are widely used in engineering education. Students cannot learn hypermedia engineering practices unless they can authentically experience those practices. One of the main challenges in teaching quality management and quality evaluation in hypermedia is to illustrate abstract and theoretical phenomena like quality experience.

The Hypermedia Laboratory is responsible for the teaching of hypermedia engineering at Tampere University of Technology (TUT). Hypermedia can be studied as a major or a minor subject, and students can focus on either the technical implementation of structured information or general design and management of hypermedia projects. This paper reports a study of a teaching experiment of Hypermedia Laboratory. The aim of the study was to develop the teaching of quality management and evaluation issues in hypermedia towards more authentic learning. First theoretical background is presented. Then the Urban Computing Lab (UCL) tool, data collection and participants are described. Third the analyses of the data and the findings are reported. Finally conclusions and suggestions for future work are presented.

\section{AUTHENTIC AND MEANINGFUl LEARNING}

Students can be motivated and supported to learn abstract and theoretical issues by offering them interesting and challenging real-world problems to solve. In order to make students' learning relevant to real-life experiences, learning environments must be authentic. Authentic learning is a process of interacting with the real world and reanalyzing and reinterpreting new information and its relation to the real world [6][7]. Authentic learning is a pedagogical approach that allows students to explore, discuss, and meaningfully construct concepts and relationships in contexts that involve real-world problems that are relevant to the learner [8].

With the UCL tool students have an opportunity to construct a meaning of a real-world context based on their own experiences in the authentic situations, which helps them to link practice with theory. When the students address the same goal, they can benefit from sharing ideas and information. The students can also control their own learning, which promotes active learning. When the learning occurs in authentic situations and contexts with examples, tasks, simulations and demonstration of complex real-world problems, opportunities for meaningful learning open up. Meaningful learning occurs when ideas and information are combined with students' own experiences to form understandings. Meaningful learning includes active, constructive, collaborative, intentional, complex, contextual, conversational and reflective dimensions. Such dimensions as transfer, motivation, volition and edutainment have been found in earlier research to enhance deep learning [8][9][10].

\section{URBAN COMPUTING LAB}

A major challenge in teaching quality management and quality evaluation in hypermedia is to illustrate how varying dimensions of context of use are related to user's quality experience. It is known that meaningful learning from real world problems enhances the learning of 
abstract and theoretical issues [8][9][10]. The Urban Computing Lab (UCL) tool for collecting and visualizing contextual information related to user's quality experiences, was designed and implemented in response to that challenge. The UCL tool is a mobile, context-aware online service to easily collect a large amount of rich contextual and emotional information from users' authentic experiences of using online services. The tool is designed to be used in the evaluation of online services for collecting information about context of use and about quality experience from a large number of users just when the online service is used [11][12].

The possibility to use the UCL tool with smart phones benefits students' learning by engaging them with realworld situations, also when observing mobile usage of online services. Only a short, 'lunch-time participation' is needed from students to collect the main information related to their quality experience in the very same context in which the online service is used. This ensures the authenticity of the information. Immediately after finishing a task, when a web page is still open in a browser window, students can click a bookmarklet, which is a small computer program for storing a URL in the bookmarks of the browser. This bookmarklet redirects to a simple web form of UCL tool with few structured questions and a couple of open-ended questions. Afterwards students can enrich the information collected in the use situation for example with annotation (textual tags), videos, pictures, narrative descriptions etc. With the UCL tool it is also easy to collect information which otherwise could be laborious such as technical information about devices or geographical position. In addition to that, the further processing of data is easier, because the information collected is in digital format.

The contextual information collected can be classified into five domains: general, physical and geographical, social, action and affective [2][11].

1. General level: user's experience of using that certain web service.

2. Physical level: information of geographical position, time stamps and technical information about devices and network connection (all collected automatically), also tags, photos and videos which describe the environment.

3. Social level: description of a social situation (is the user alone, using the service with a friend or are there any people around if she/he needs help).

4. Action level: information which describes users' actions (what a user is doing, which web service she/he is using and the purpose of use, success of use).

5. Affective level: information about a user's feelings and emotions (overall and connected to use).

With the reporting system of the UCL tool students can generate simple diagrams for illustrating contextual factors related to the users' quality experience of a certain online service, for example by investigating averages of answers given as in the case of TUTCircle, which is a web based environment for students offering customized tools for enhancing social aspects of student life at TUT [13]. See Fig. 1. According to a report generated by the UCL tool it can be found that mean score of quality is 2.6 and mean score of utility is 2.0 (on a scale 1-5). Most of the students' overall feeling of the day were 'satisfied', and

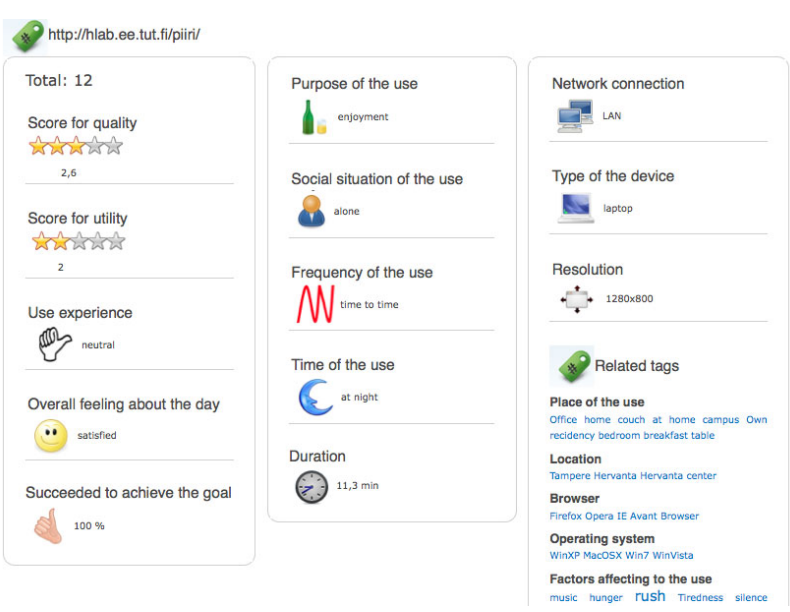

Figure 1. Averages of answers given by 12 students to questions about contextual dimension related to the quality experience of using the web service TUT Circle http://hlab.ee.tut.fi/piiri

their use experiences was 'neutral'. Most of the students used the online service for enjoyment at night with a laptop in their homes situated in Hervanta district Tampere. All the students succeeded in achieving their goals.

The UCL tool also offers possibilities for a detailed examination of each use experience or for a comparison between them. A teacher can, for example, select and sort information according to predefined criteria to gather information on certain kinds of use experience. This kind of report can illustrate a variety of the quality experiences to the students, and help them to understand why users' feedback on quality issues differs. See a screen capture of the report in Fig. 2. There is a list of six cases of using the TUTCircle online service. The information about the contextual factors related to the quality experiences is selected according to respondents' overall feelings about the day, which were 'bored'. In the columns reading from left to right: 1 . user's goal for using online service 2. URL of online service 3 . user's overall feeling about the day 4 . score for quality 5 . score for utility 6 . quality of use experience 7. achievement of goal 8. duration of using online service 9. place for using online service 10. type of device.

The information about the contextual dimensions related to quality experiences collected with the UCL tool can be easily exported from the tool for further analysis with, for example, SPSS (Statistical Package for the Social Sciences) or SNA (Social Network Analysis) software.

Especially in the educational context products or software should provide high quality experiences so that users can concentrate on learning instead of struggling with interface. The user consciously or unconsciously evaluates the pragmatic and hedonic quality of the software. Pragmatic quality indicates how effective, usable, clear, useful or controllable etc. the software is. Hedonic quality indicates if the software is stimulating, communicates identity and invokes memories. Stimulating software meets the individual's needs for personal development, i.e., the development of skills and knowledge. To be stimulating, software must provide novel, interesting or exciting interaction or content [14] [15]. 


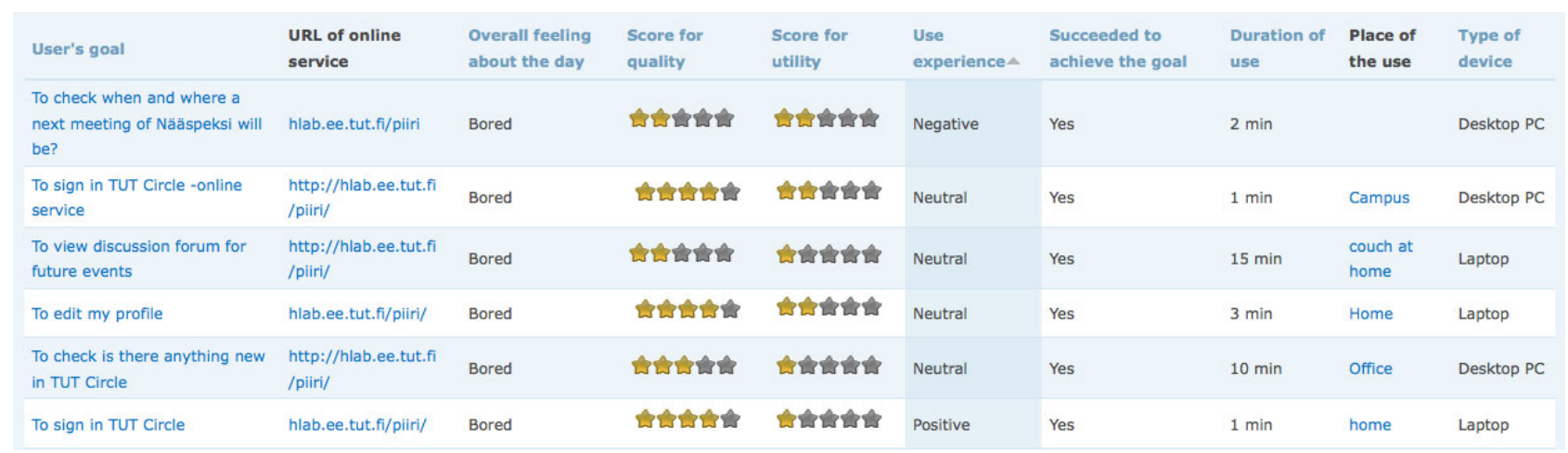

Figure 2. With the reporting system of the UCL tool various reports and compilations of information collected an be generated for detailed examination or comparison between use cases. In the figure the information about the contextual factors related to the quality experiences of the TUT Circle online service is selected according to respondents' overall feelings about the day, which were 'bored'.

The students' conceptions of the pragmatic and hedonic quality of the UCL were examined using the AttrakDiff ${ }^{1}$ questionnaire. AttrakDiff is an instrument of measurement in the format of semantic differentials, which are items with poles of opposite adjectives like conservative innovative. Respondents can rate a product or a web service on 7 semantic differentials for each dimension of user experience with a 7- point Likert scale [15]. According to the results of this research a major part of students $(81 \%)$ considered the pragmatic quality of UCL to be positive, and the tool to be easy to use. None of the students considered pragmatic quality to be poor. Half of the students $(51 \%)$ considered the hedonic qualitystimulation of UCL to be positive. They regraded UCL as an innovative, inventive and novel tool. A quarter of students $(24 \%)$ considered the hedonic stimulation of UCL to be negative. They thought that UCL was an undemanding, dull and cautious tool with "ordinary questions" and "nothing new" [16].

\section{TEACHING EXPERIMENT}

This research was carried out in autumn 2009. There were 34 students of Tampere University of Technology participating in the research. They all had hypermedia as their major subject, and they all participated in the same university course entitled "Usefulness of Web-based services".

Two assignments were presented to the students at the end of the course, after the students had learned about quality evaluation of online services in several lectures. During the lectures, theoretical backgrounds of quality experience and online service quality evaluation as well theories of usability, accessibility and informational quality were presented to the students. The students also studied different evaluation models, they familiarized themselves with different evaluation methods and they practised using different kinds of evaluation criteria, checklists, standards etc. when doing their weekly exercises. The research ascertained if the use of the UCL tool helped students to understand how and why different users prefer different properties of online services and why users' feedback on quality issues differs.

As Exercise 1 the students were asked to use a freechoice online service and save the contextual information related to their quality experience using the UCL tool, and

\footnotetext{
1 AttrakDiff ${ }^{\mathrm{TM}}$ a service of User Interface Design http://www.attrakdiff.de/en/Home/
}

to write short essays on the strengths and weakness of using the UCL tool for the quality evaluation of online services. The students were not told beforehand anything about the purpose the UCL tool was designed for. Only short, practical guidance on how to use the UCL tool for collecting information was presented to them. The main aims of this assignment were to let the students familiarize themselves with the tool, and by analyzing their essays to find out how they plan to use the tool for the evaluation of online services and why. It was of interest to find out if the students realized why all this contextual information was needed when evaluating quality experiences.

One week later (as Exercise 2) the students were asked to use the same online service, but now they were asked to change the context of use in some way by changing devices, environment, social situation etc. After that the students were asked to compare their earlier experience with the later one, and to find out if there were differences between those two experiences and why. As before, the students collected the information using the UCL tool and wrote short essays on their findings. Once again the students' essays were analyzed to find out if the students found any differences between their first and second experiences. It was also of interest to find out if the students saw any connection between their quality experience and the contextual factors affecting the use situation. Our hypothesis was that students develop a better understanding of the significance of contextual dimensions for the quality experience by analyzing their own real-life quality experiences.

\section{ANALYSIS AND RESUltS}

The students' essays in Exercise 1 were analyzed by using a two-level approach. At first the explicit meaning of the each essay was found i.e. what the student exactly wrote about, for example, using the UCL tool for evaluation purposes. Secondly, the implicit meaning of the essay was analyzed by using content analysis, which is a technique for identifying specified characteristics of text (content) objectively and systematically [17]. During the process of analysis, potential features and indicators were identified related to the student's views on the quality experience and the contextual factors. Based on the interpretations of these features and indicators, a conception of student's understanding of quality issues was formed. The purpose of this was to find out what the students had actually learned; did they understand how to 
use the UCL tool and for what purposes, and how did the different contextual factors affect the quality experience.

The students' essays in Exercise 2 were analyzed in the same way as the essays in Exercise 1. The purpose of the analysis was once again to find out what the student had actually learned, but also to find out if the comparison between the information collected from two different quality experiences helped them to understand how the different contextual factors are related to the quality experience.

After the analysis of the essays the students were grouped according to their learning outcomes. According to the learning outcomes of the first exercise the students can be grouped into three different groups: 1. students who think that only some of the contextual factors related to physical level like device, browser and display resolution could impact on quality experience, 2 . students who emphasize usability and accessibility and pay attention mostly to the factors related to action level 3 . students who understand the contextual factors impacting on quality experience can be related to general, physical, social, action or affective level. Percentage distributions of students by learning outcomes were also calculated.

Group 1: The analysis shows that after the first exercise as many as $27 \%$ of students did not understand at all how and why to use the UCL tool for quality evaluation. Most of these students thought that the UCL tool was a selfreporting tool for user or evaluator experts to save notes about their using experience for further use. However they did not understand what benefit that could offer, and they did not discover the possibility to use the UCL tool for collecting information from large numbers of users. According to the students there was an insufficient number of questions included in the UCL tool, and the questions were not specific enough for serious quality evaluation. Some of them were thought that for evaluating quality of web service it is enough to know about device, browser and display resolution, so only some of the contextual factors related to the physical level could impact on quality experience.

"I think that the UCL tool is quite useless... ... It is not possible to use the tool for collecting detailed information about use experience. The UCL doesn't offer any information on how to improve (the web service) in case the use experience has been poor..."

"According to my opinion they emphasize geographical position and environment of use too much - instead of device, browser and display resolution factors like position or frequency of using web service should not influence use experience...."

Group 2: Forty-three per cent of students understood that the UCL tool can be used to collect information on the user's experience, but they did not understand why certain contextual information was collected. They thought that features of the online service and success of the users in achieving their goals are the most important things to pay attention to, when the experience of using an online service is evaluated. Most of these students emphasized usability and accessibility factors and wondered at questions about feelings, arousal or social context.

\footnotetext{
2 The responses of participants were originally in Finnish, and they have been translated into English.
}

“... quality evaluation of tired or angry user, who is often impatient, can be more critical than the quality evaluation of rested user, who is not in a stressful situation. Nevertheless these are unique characteristics of the user or the test case, which should not be allowed to distort the results of quality evaluation."

Group 3: Only $30 \%$ of students understood how to exploit the UCL tool for collecting contextual information from a large number of users for further analysis of users' quality experience. They also realized the importance of collecting different information related, for example, to emotions, arousal level, physical and social environment for evaluating users' quality experiences and variation of these experiences.

"Only the most relevant questions have been included in the tool, therefore it offers a very concise, informative and exhaustive picture of use situation.... The UCL tool is a very useful tool for evaluator experts to collect information from users in quick and effective way for further analysis. "

"I hadn't realized before how the overall feelings of a day could affect my experience of pleasure related to the use of a web service, which is obvious on the other hand. In addition the UCL tool made me think how many different factors could disturb the use of a web service. For example: The TV is on, my stomach is rumbling, the rain patters on a window. The UCL tool also offers a chance to compare the user experiences of different users. It is also possible to find out how the users have responded to the questions about different web services. That helps me to notice which web services are of high quality according to users. "

As the second exercise the students used the same online service as before, but now they changed the use context in some way. Once again after the analysis of the essays the students were grouped according to their learning outcomes into three different groups: 1. students who seemed to think that contextual factors do not affect on quality experience, if the online service is usable enough 2. students who understand that contextual factors related to physical level can affect quality experience 3 . students who understand contextual factors impacting on quality experience can be related to general, physical, social, action or affective level. The percentage distribution of students by learning outcomes was also calculated. Finally the degree of the association between the students' course grades and students' learning results were measured using Spearman's rank correlation, which is a non parametric test for indicating the direction of association between variables in ordinal form.

Group 1: After the second exercise according to the results of the analysis there were $20 \%$ of the students, who did not perceive any differences between their two experiences despite differences in the context of use (different device, quiet vs. noisy environment, busy cafeteria vs. tranquil home). In their analyses they focused mainly on the features of online services, which they examined from the viewpoint of usability and accessibility. When the online service is easy and effective to use despite the devices, the browsers or other technical issues, the other contextual dimension has no significant impact on the quality experience. In other words they seemed to think that online service with high usability and high accessibility can offer high quality experience despite the varying context of use. 
"I didn't find any differences between use situations. I used the web service first at home in a peaceful atmosphere, and later in a lively clubroom. That had no affect on my use experience because the task was very simple with clear guidance."

"I used the same web service first at home on a Windows- PC, and the second time at a cafeteria using a Nokia N810 Mobile phone. ... It took a little bit more time to achieve my goal using a mobile phone than using a desktop PC. Loading the web page, navigating on the page and writing the text were slower. The difference was too unimportant to reflect in quality scores."

The rest of the students $(80 \%)$ perceived the change in their quality experience caused by contextual factors related to one or more contextual level (e.g. general, physical, social, action or affective).

Group 2: Sixteen per cent of all students mentioned one or two factors related to physical level. They had noticed that their quality experience was different depending what device, browser and physical environment with disturbing factors like noise, time of day.

"The web service wasn't able to be used properly by mobile phone, which has a very negative impact on my quality experience."

Group 3: Contextual factors related to the two or three different levels of contextual information were mentioned by $63 \%$ of all students. All of them mentioned factors of physical level like device, browser, noise or other disturbing factor related to physical environment. Two of three from those students had noticed that their emotional state and level of arousal also affected their quality experiences.

"The change in my quality experience was not caused by a different device or different social situation. The main explanation for that change is the change in my feelings. The time of day and the day program were the same. The last time I was tired and stressed because of all the school work, but today I feel energetic and excited about this exercise. "

"Today I feel so good and energetic that noise from the TV or the conversation with my friends didn't disturb me from concentrating on shopping in the web shop."

Some of the students reported that contextual factors of social level had a significant impact on their quality experiences and that this experience could be positive as well as negative.

"The main explanation for the difference between my quality experience was the social situation. The other people at the same table in the cafeteria attracted my interest for the moment, which disturbed my use of the web service."

"Now I was browsing the web pages with my friends. It was much more comfortable to search for certain kinds of components together with my friends and discuss."

According to Spearman's rank correlation test the association between the student's course grade and the student's learning outcomes was positive and moderate (rs $=0.449)$. The association was statistically significant $(\mathrm{p}<$ 0.05 ). The more numerous contextual factors a student mentioned, the higher was his/her course grade. However, this correlation cannot prove anything. Further research is needed before we can prove that one thing affects the other. It nevertheless suggests a connection.

\section{DISCUSSION}

People solve problems in their everyday lives and naturally build their own theories to explain the world, therefore it can be claimed, that problem solving is always authentic. When people are trying to solve a problem, they construct and test a mental model of the concepts related to the problem. The knowledge constructed in the context of problem solving is more integrated, more transferable and better integrated than knowledge constructed on traditional lessons. In the learning context problems can provide a purpose for learning new things, which is also important for meaningful learning. It can be said that problem solving provides meaningful forms of knowledge [7] [8] [9].

In order to develop the teaching of quality management and evaluation in hypermedia toward more authentic and more meaningful learning, the Hypermedia Laboratory organized a teaching experiment during which the students were offered real-world situations to analyze. The students were asked to use a free-choice online service and to consider if any factors related to the use situation affected their quality experiences. They used the UCL tool to collect information related to their own quality experience in the authentic situation, and saved that information for later analysis. The analysis of the information from their own experiences helped students to link the practice (their own experience) with the theory of the quality experience [8][9]. This helped the students to understand the elements of the complex and abstract phenomena like quality experience, to develop concepts, and by using these concepts to structure a mental model, which is the mental representation of the phenomenon and its elements [9][10]. According to the analysis of the essays from the first exercise it can be said that all the students were able to see the connection between their quality experience and contextual factors in some way, but only $30 \%$ of the students seemed to fully the understand relationship between the quality experience and the contextual factors. For the $70 \%$ of the students an idea of contextual factors' impact on quality experience seemed to be new, even though they had studied the theory of those in traditional lectures. They still had the "old" mental model of the concepts related to the quality experience. For example, it can be assumed that $43 \%$ of the students emphasized usability and accessibility because they had studied these issues on other courses, and they had not yet developed a new mental model.

The conceptual change required for problem solving and learning occurs through experience and reflection. Before the students were able to solve the problem how the contextual factors and which of them affected to their quality experience, they needed to understand the causal relationship among the concepts related to the phenomenon, and to adapt and restructure those concepts to build a new personal theory of quality experience [9]. After the second exercise the students compared the information from the first exercise to the information from the second one. This comparison strengthened the connection between practice and theory, helped the students to understand the causal relationship between the concepts, and to reorganize the concepts to restructure a new mental model of the phenomenon to develop the personal and unique understandings of the quality experience [8] [9]. After that, the students discussed about their own experiences with each other. This dialogic 
process informed by experiences and course readings supported the students to integrate ideas and knowledge that had been received by the group. Through reflection and discussion the personal understandings of students were transformed into shared understanding.

When after the first exercise only $30 \%$ of the students seemed to fully understand the connection between their quality experience and the contextual levels, after the second exercise $80 \%$ of the students perceived the change in their quality experience, and they seemed to understand the idea of the impact of contextual factors on quality experience. The students' learning outcomes were better after the second exercise than after the first one. In addition, the learning outcomes of the second exercise seem to indicate students' success. According to Spearman's rank correlation test there was a moderately positive association between a student's course grade and a student's learning outcomes. The more numerous contextual factors a student mentioned, the higher his/her course grade was. However, this correlation cannot prove anything. Further research is needed before we can prove that one affects the other.

\section{CONCLUSION}

In the quality evaluation of web services students usually pay attention to usability issues (is the web service easy and efficient to use, easy to remember, has it few errors and is it subjectively pleasing). During the teaching experiment in autumn 2009 the UCL tool was used to make the students also pay attention to contextual and situational issues such as user's goal for using an online service, user's overall feeling about the day, opinion of the utility of the service, use experience, achievement of goal, duration of using online service, place for using online service, and type of device. The research emphasized that most students needed guidance in taking account in evaluation of contextual dimensions like social level (description of a social situation - is the user alone, using the service with a friend or are there any people around if she/he needs help), action level (information which describes users' actions - what a user is doing, which web service she/he is using and the purpose of use, success of use) and first of all affective level (information about a user's feelings and emotions - overall and connected to use).

In conclusion we can argue first that students can be motivated and supported to learn abstract and theoretical issues by offering them interesting and challenging realworld situations, and that the UCL tool, which students regarded as pragmatic and easy to use, seem to be convenient for that purpose. Secondly we can argue that meaningful learning from real-world problems in authentic contexts provides a more effective learning opportunity for students than traditional lecturing. The analysis and comparison of their own experiences from authentic real-world situations for solving complex problems helped students to develop a new mental model of the phenomenon, and in that way helped them to learn and better understand the abstract and theoretical phenomena like quality experience. However, $20 \%$ of the students seemed not to understand the relationship between the quality experience and the contextual levels. These students might need more opportunities to compare and solve problems in collaboration with other students. They could benefit from simulations of real world situation of professionals, which offer students more authentic situations with activities, problems and events drawn from the real world of professional practices. The narrative models of practices with complexity, contingencies and dilemmas could promote analytic discussion, active participation, problem solving and critical thinking by providing a richer variety of opportunities to learn through analysis and discussion of ill-structured problems, sub-goals, plans and management of workflow etc. [18]. However, further research is needed in the efforts to better understand if the students could benefit from the simulations of real world situation of professionals and how to support the students to improve their learning outcomes in general.

\section{REFERENCES}

[1] J. Nielsen, Usability Engineering. San Francisco, CA: Morgan Kaufmann, 1993.

[2] J. Keldskov, and J. Paay, "Public Pervasive Computing: Making the Invisible Visible," IEEE Computer, vol. 39, pp. 60-65, September 2006.

[3] D. Norman, "Emotion \& Design. Attractive things work better," Interactions Magazine, vol. 9, pp. 36-42, issue 4, 2002.

[4] V. Surakka, "Tunteet ja sosiaalisuus ihminen-tietokone vuorovaikutuksessa," Psykologia, vol. 39, pp.19-28, issue 1, 2004.

[5] K. Silius, and A-M. Tervakari, "Variety of quality experiences on web-based courses," in Proceedings of the 7th IEEE International Conference on Advanced Learning Technologies ICALT 2007, Niigata, Japan, J. M. Spector et al., Eds., July 2007, pp. 858-861.

[6] J. S. Brown, A. Collins, and P. Dugui, "Situated cognition and the culture of learning," Educational Researcher, vol.18, pp. 32-42, issue $1,1989$.

[7] J. Lave, and E. Wenger, Situated learning: Legitimate peripheral participation. Cambridge, MA: Cambridge University Press, 1991.

[8] M. S. Donovan, J. D. Bransford, and J. W. Pellegrino, How people learn: Bridging research and practice. Washington, DC: National Academy Press, 1999.

[9] D. H. Jonassen, "Taxonomy of Meaningful Learning," Educational Technology, vol. 47, pp. 30-35, September-October 2007.

[10] S. Järvelä, and H. Järvenoja, "Students' motivation in technologysupported environments - Aspects of self-regulation and volition," in Lernprozess, Lernumgebung und Lerndiagnostik, M. Wosnitza, A. Frey and R.S. Jäger, Eds. Landau: Verlag Empirische, 2004, pp. 139-149.

[11] K. Silius, A-M. Tervakari, and T. Miilumäki, "Learning by doing as mobile with Urban Computing Lab," in Proceedings of International Technology Enhanced Learning Conference TELearn 2009 Taipei, Taiwan, October 2009 [CD-ROM].

[12] F. A. Hansen, and N.O. Bouvin, "Mobile Learning in Context Context-aware Hypermedia," International Journal of Interactive Mobile Technologies (iJIM), vol. 3, January 2009.

[13] K. Silius, and T. Miilumäki, "Students' Motivations for Social Media Enhanced Studying and Learning," in Proceedings of International Technology Enhanced Learning Conference TELearn 2009, Taipei, Taiwan, October 2009 [CD-ROM].

[14] M. Hassenzahl, "The thing and I: understanding the relationship between user and product," in Funology: From Usability to Enjoyment, M. Blythe, C. Overbeeke, A. F. Monk and P. C. Wright, Eds. Dordrecht: Kluwer Academic Publisher, 2003, pp. 31-42.

[15] M. Hassenzahl, A. Beau, and M. Burmester, "Engineering Joy," IEEE Software, vol. 18, pp. 70-76, January-February 2001. doi:10.1109/52.903170

[16] A-M. Tervakari, and L. Lähteinen, "Käyttäjien suhtautuminen UCL- ympäristöön," unpublished.

[17] M. C. Patton, Qualitative Research \& Evaluation Methods, 3 rd ed., Thousand Oaks, CA : Sage Publication Inc., 2002. 
[18] J.M. Carroll, and M. B. Rosson, "Toward Even More Authentic Case-Based Learning," Educational Technology, vol. 45, pp. 5 11, November-December 2005.

\section{AUTHORS}

A-M. Tervakari is with the Hypermedia Laboratory, Tampere University of Technology, Tampere, Finland (email: anne.tervakari@tut.fi).
K. Silius is with the Hypermedia Laboratory, Tampere University of Technology, Tampere, Finland (e-mail: kirsi.silius@tut.fi).

This work was supported in part by the European Social Fund.

This article is an extended version of a paper presented at the IEEE EDUCON20211 Conference, held from April 4th-6th, 2011, in Amman, Jordan. Submitted, April $20^{\text {th }}, 2011$. Published as resubmitted May $2^{\text {nd }}$, 2011. 